\title{
Sheffield

\section{Transports of delight? What the experience of receiving (mobile) phone calls can tell us about design}

LIGHT, Ann

Available from Sheffield Hallam University Research Archive (SHURA) at: http://shura.shu.ac.uk/2118/

This document is the author deposited version. You are advised to consult the publisher's version if you wish to cite from it.

\section{Published version}

LIGHT, Ann (2008). Transports of delight? What the experience of receiving (mobile) phone calls can tell us about design. Personal and Ubiquitous Computing, 12 (5), p. 391.

Copyright and re-use policy

See http://shura.shu.ac.uk/information.html 
Transports of Delight?: What the experience of receiving (mobile) phone calls can tell us about design

Ann Light

Interaction, Media and Communication Group, Dept of Computer Science

Queen Mary, University of London,

annl@dcs.qmul.ac.uk

Abstract

This paper takes a phenomenological approach to analysing people's accounts of receiving phone calls, drawing on Heidegger and Feenberg. Accounts of calls received on a mobile phone are compared with those on landlines, charting progress from location-centred to person-centred phoning. A range of naturally-occurring contexts are discussed in terms of the experience of balancing the activities of talking on the phone with activities in the immediate environment, and the enchantment sustained or sacrificed. The study suggests that recipients' enchantment with phoning is affected by their freedom and desire to project towards the caller and create shared spaces, and reveals some factors that impact on the transitions of attention required to do so. It concludes with the design implications of taking this view of interactions with and through phones.

Keywords: context, phenomenology, mobility, personal phone, space, recipient

Introduction

Anyone watching a young child first talk to an absent parent on the telephone will be reminded of what a peculiar thing it is to hear a familiar voice come out of a small box. The sense of mystery and awe dispels as we grow used to the phenomenon.

But phonecalls still have magic. This paper looks at people's experiences when speaking on the telephone: considering the mechanism of phoning; what enchantment two people can provide for each other by engaging in this way; and what disrupts that connection. In doing so, it addresses the move from location-centred to person-centred phoning that comes with the advent of wireless phones and the impact of mobility, taking a phenomenological perspective. These issues are discussed in the context of their design implications.

\section{Researching the telephone}

An analysis of people's descriptions of their experiences receiving phone calls is offered as a complement to conversation analytic accounts of phone use ([1],[2]), which place particular verbal behaviours in context, and to the sociological approach of interviewing people about behaviour with phones (eg [3]). But mobile phones have attracted research attention of several kinds. As much information appliance [4] as phone, they gain some of their attraction from features that landlines do not share. New practices have appeared in response to new functions, such as texting, and offer new behaviours to analyse (eg [5]).

Other studies explore the social behaviour that emerges from the use of a mechanism that is closely associated with the individual - eg [6] on status, and [7] on sharing. Vincent [3] considers the strong attachment that people can feel to their mobile phone, attributing it to their sensory experience of engaging with and through the object, in addition to its role as a conduit for activity between people who already have some form of relationship. McCarthy et al [8] deal specifically with mobile phones in their study of enchantment. They align with Vincent in seeing phones as emotionally and sensually significant to their users and comment on the active construction of conditions for enchantment, contrasting this with film, where the depth and potential for enchantment are contributed by the makers. Another strand of work starts with people's mobility, looking at how this is affected by the possibility of communication on the move, either at a structural level, or in terms of the individual's relationship to place, location and social group - eg [9], [1] and [10], or [11] on the tension between the virtual context of the call and the actual 
context of the conversants.

But there has been little discussion of the experience of phoning or how it has changed now that phones are "with you all the time" (226) [3]. Phones are now associated with individual voices. Mobility is becoming an arbitrary feature - accepted as obvious; used as needed. Phones as personal property are as mobile as we are, and it is this quality - allowing us to situate calls almost anywhere and then move while still talking - which alters our understanding of the range of physical relationships we can hold. This integration manifests in another way: a secondary transition is progress towards close-coupling with the body. Phones are smaller and increasingly inconspicuous. Five years ago, they were pulled out of the bag or pocket. Now many are used while attached to the body, experienced as hands-free earpieces, or through headphones and a microphone suspended at the neck. They are fragmenting and associating with individual bodily functions (such as the separate Bluetooth earpiece in the ear). These changes may be largely a desire to integrate their use with other mobile technologies. The phone, as well as introducing new functions and practices such as texting, is being incorporated into existing mobile practices such as driving, or listening to music as one walks, and this has changed the relationship of person to phone again.

So, how has the experience of being-on-the-phone changed as the phone has moved from beyond the person, to with or on the person? What do these transitions mean for people's capacity to make connections - not in the technical sense of end-to-end reception, but in the qualitative sense of connecting with another person? How do shifts between person and phone bear on the relationship between the people involved in the call? This paper seeks to raise the questions in the context of a study of experience and enchantment.

\section{Phenomenological perspectives}

The relation of person to person in phoning is peculiar, as the introduction notes. To understand why it is not strange to perform such a peculiar activity, we can look to the nature of closeness and distance as conceptualised by Heidegger.

Heidegger dismisses the Cartesian space of GPS co-ordinates as a construct that comes out of far more intrinsic experiences of spatiality. He contrasts the remoteness of the street - in contact with our shoes, but uninteresting to us - with the acquaintance we meet upon it. The latter is phenomenologically closer because it is to them that our attention goes as we notice them: interestedness or concern at the time 'brings something close by' (141-2) [12]. As Dreyfus [13] puts it: 'for Heidegger for something to be near it must be both something I am coping with and something absorbing my attention' (134). Coyne [14] takes this perspective into the context of people connected by phones: the commuter on her mobile phone is measurably close to her fellow travellers in the railway carriage but nearer ontologically to the person on the end of the phone.

If we now look at the second relationship, of the person to the technology, we turn the telescope round. Rather than bringing close, the act of using something effortlessly and concentrating elsewhere sends the medium into inconspicuousness. It takes a breakdown in immersion in our activities for us to notice peripheral features. Heidegger discusses the tools of sensory enhancement in this context: 'equipment for seeing - and likewise for hearing, such as the telephone receiver - has what we have designated the inconspicuousness of the proximally ready-to-hand' (141) [12].

Sometimes, as Heidegger illustrates famously with a hammer, it is the unexpected behaviour of a tool that demands our attention. However, the phone is again revealed to be a curious, though not unique, type of tool in deliberately causing breakdown. By (usually) ringing to signal an incoming call - behaviour generically expected from a phone it demands a sudden refocusing, away from what was concernfully interesting to the recipient of the call before the ringing started, and towards the ringing object. Further adding to the complexity, the action of demanding a change in attention is not the primary role of the phone, unlike, say, the alarm clock. The duration of the ring is, in effect, the preparation time available to the recipient before an answer is expected of them. But that ringing is also the beginning of the disruption to whatever the recipient was doing.

Where Heidegger illuminates the individual's focus when using technology, Feenberg discusses the 'extended body' created by using technology. Feenberg [15] characterises the 'extended body' as a form of passive bodily experience, drawing on Merleau-Ponty's notion of habituation through integration of tools. The extended body not only acts through a technical mediation, but also signifies itself through that mediation: we can be revealed by our protheses as 
well as by our bodily presence. One of Feenberg's examples here is 'the ringing of the cell phone that [announces and] embarrasses us in the middle of a lecture' [15]. Feenberg offers the technologically extended person as the object of concern, concluding with analysis of online writing: 'mediated human contact is always measured against full bodily co-presence, however, the consequence of this situation is not simply a feeling of loss but evokes compensatory efforts to fill in the gaps'. To paraphrase, our extensions are perceived, and, thus, acted upon, by others. The visible (or 'hearable') parts of the extended body, when stripped of other information, may be an invitation to elaborate. The physical body need only be involved as a trace; offering the seduction of something discernibly incomplete to interpret.

Enchantment, disenchantment and phenomenology

Describing the phenomenology of enchantment, Bennett [16] says: 'To be simultaneously transfixed in wonder and transported by sense, to be both caught up and carried away - enchantment is marked by this odd combination of somatic effects.' McCarthy et al [8] talk of the contradiction inherent in enchantment: 'although we are disoriented, perception and attention are heightened.'

If we relate these descriptions of enchantment to the phenomenologists' understanding of space, we can see an interesting parallel in the projection of where our interest takes us (Heidegger's 'concern') and the transports of sense that enchantment involves. Further, according to Feenberg, in using media - with their suggestion of and conduit for remote connection to others - people sometimes invest in enhancing each other: filling in the gaps in the media representation. Evidence of this kind of work could be seen as a symptom of being caught up and carried away, of heightened perception and attention.

Can we argue that the phone dis-orientates in this way? If we can find evidence for willing shifts through phenomenological space and attention focused on constructing another body from a trace we have a strong argument for enchantment. And then we can ask: what causes breakdown?

Enchantment, at its crudest, is domination by a more powerful agent. In fairy tales, spells must be broken so that attention can be returned to the mundane. There are issues of control involved. So other questions follow: when is breakdown inevitable, or even desirable? When might the heightening of remote attention be a bad or frustrating thing?

Most phenomenological literature has considered phones as enabling, allowing people to talk at will. But the twoway nature of phones is disregarded. Spectacles or a hearing aid always enhance, whereas a phone on your body is a connection both when you wish to be connected, but also when others wish to be connected with you. Can it do more than embarrass in lectures? Can it disrupt at a highly personal level? Is the phone intrinsically disenchanting for call recipients? To open up this area to scrutiny, interviewees were asked only to give accounts of receiving calls.

\section{Method}

To recap, the section above shows that there is good reason to interview people in their role as recipients. Then, to reveal something of the importance of the phone's relationship to the person, interviewees were asked to speak about using both mobile phones and landlines so that their experiences with each could be compared.

Emphasis was placed on the openings and endings of each call, an emphasis seen in work on telephone calls from [17] to [2]. However, the reason for this emphasis was not to look at how participants orientate towards each other [1], but rather to look at how one participant orientates towards the phone and the fact of the incoming call.

\section{Participants}

Exploring these issues, 10 people - a mixture of male and female British professionals - were interviewed about some 24 phone calls they had received. All were aged between 30 and 50 and all were regular users of landlines before adopting mobiles. This profile was chosen to throw attention upon what mobile phoning has introduced to those for whom it was a transition from landlines, as opposed to a younger group for whom mobiles have always been part of the landscape.

For this study, people were chosen who (1) regularly use both kinds of phone as part of their social and work life, 
and (2) are used to explaining their ideas. Seamon [18] argues that when using what he calls 'an existentialphenomenological approach' some people will be more appropriate than others to invite as participants. Chosen participants met his two conditions: that they (1) must have had the experience under investigation; and (2) be able to express themselves clearly and coherently in a form relevant to the investigation.

\section{Interviewing}

Participants were asked to describe the last time they received a mobile call and the last time they received a landline call. After giving both accounts they were invited to compare the two experiences of remembering, commenting on what they had learnt. In this way, some comparison was possible without affecting initial recall.

No formal structure was imposed. Interviews were non-directive in order to gather accounts in the participants' own words about what they felt was relevant to mention. People were encouraged to describe the phenomena under review in considerable detail and pressed to evoke the events and thoughts that had been part of the experience in receiving the calls, using the technique described in [19] and [20]. By using evocation, the method gets as close to an immersive form of recollection as is possible to create in the essentially reflective space of an interview. The first extract from an account, in the section below, is quoted at length to give a flavour.

A retrospective interviewing method acknowledges the importance of discussing naturally occurring phenomena so that motivation, expectation and other contextual factors that inform experience are not distorted before the event. This precluded recording the calls involved. One feature of this technique is thus the absence of control over the contexts of the experience being described. Calls ranged broadly from the unanswered, to a message centre call-back, to an involved discussion with an old friend, to a series of calls to find someone, to sales calls, to the query of an unknown journalist.

A broad outline of the equipment used was gathered so this could be considered in relation to the experiences described. Obviously, equipment is an influencing factor. For instance, in comparing fixed and mobile phones, any ring tones personalized to the caller extend the impact of "caller ID", which, being common on mobiles and rare on fixed lines, already serves to alter the phoning experience by revealing ahead of answering who is calling.

Analysis

The accounts were transcribed and analysed as examples of discourse. This discourse was treated as relating to the experience of the phone calls, but it was not construed to be either the experience itself, or representative of the calls in more than a general way.

The accounts were then scrutinised for the kind of discovery that might be useful in informing phone design. For instance, the structure of the accounts was of interest for what it might reveal about the shifts in attention of the individual (see [20]).

\section{Experiences of Enchantment}

Here are two accounts of being on the phone. The initial one is taken from an account of receiving a landline call (and, as noted, will be quoted at length to demonstrate the style of questioning as well as the responses). The second involves a mobile phone.

It's odd. When you know the person so well you almost think they are in the same room as you. You forget that you've got a phone in your hand.

\section{When do you have that experience?}

When I'm having a really long phone conversation. I can speak for hours on the phone to some of my girlfriends. It's like...

It's like...?

It's like she's in the room. 
Ok, tell me more about that... is that a feeling or a...?

I can visualise where she's sitting because I know her house. That's really important. And I know her really well, so there's never any awkward moments. I guess the phone - it just disappears. It disappears. It's odd, I've never thought about that before.

When you say it disappears - tell me about that?

I mean, it's not the most important thing in the room at the time (laughs a lot, embarrassedly) and I'm much more interested... it's because you are doing the same thing with it all the time.

It's quite difficult trying to describe the process of noticing something disappear..

Yes! (laughs) Absolutely. It's not bugging. I've got a pretty odd-shaped, heavy phone because it has the handset built in. And it doesn't become... it's just, its not awkward, it's a familiar position, no one says 'oh, I can't hear you properly, can you move your phone'. I think I've just become one (laughs) with my phone. (HG, landline)

Here HG captures both the inconspicuousness described by Heidegger and something of Merleau Ponty's habitualisation. She goes straight on to give a vernacular account of 'bringing close' and of Feenberg's 'filling in':

You are actually in two places at the same time, and it's not real space. And, um... you've created the third space, because you've got a dialogue going which, if you shut your eyes, you wouldn't be in any one of those two places. ....[She] might say 'I'm just giving the dog a bone' or something like that and I know what the dog looks like and I know what a bone looks like, I know what she looks like, I know what her front room looks like - I can see the whole thing happening, whereas I can't actually see it, it's in my mind's eye and if I shut myself down from my own room by shutting my own eyes, I can be there, pretty much. (HG, landline)

She is not alone, as another interviewee indicates:

All the way through the call I'd been really focused on her and my presence in the place where I was was really rather bodily - it was like the shape of me but actually I was somewhere else in this kind of non-space which was the space of my phone call. But at the very end of the call, in the office, I was just suddenly really aware of everything around me. (CS, mobile)

The phone is present; the person talked to is not - only their 'extended body' might be construed to be. But in HG's account, the phone has disappeared and she is busy filling in the person's life at the other end. All her thoughts are with her friend - her 'concern' is for her. And she has projected herself into a space that reflects the locus of her interest. Both interviewees suggest that they have, in some sense, relocated into a new space. For the most part, nothing in the immediate environment is relevant or attended to. This is made clear by the second interviewee, CS, pointing to the moment when her interest in her immediate context begins to reassert itself. Her interest is ahead of her activity, as Heidegger observed.

This is the spell that a phone conversation can exert. It can take people out of their immediate context and have them conjuring images of physically distant spaces and people. They can be caught up and carried away. If this experience is the extreme of engagement through a phone - and there was nothing in the interviews to suggest that a qualitatively different form of full engagement was possible - then we can use this 'enchantment' as the standard against which to measure other experiences.

It is worth noting, before moving on, that this enchantment is possible independent of where the speaker is (HG: home; CS: office, walking to the office) and whether they are using a fixed line or a mobile phone. It is also worth noting that the phone is merely the enabling device - the contact and the conversation are here the sources of enchantment.

Other interviewees referred to imagining the caller and the caller's context as part of taking the call:

That consultant I was setting up a meeting with, I know she's got a small office, works from home. I've never been 
to her office but I've always had in my mind's eye a picture of what it's like and that's what I had in my mind's eye when I was talking to her. (SZ, landline)

One interviewee (JM) described having an image of who was speaking and where this person was in one call (received on a landline from someone that she knew), but not in the next, when a stranger rang her mobile and there was a lot of interesting local noise to distract her. Although both calls arrived in her workplace, her activity and the caller varied sufficiently between the two calls to account to her satisfaction for her qualitatively different attention. Here we have a clear indication that enchantment is related to contextual factors.

But not everyone immersed themselves fully in their calls even when they had a peaceful environment around them and were talking to a friend. Here is someone using a wireless landline phone:

I was out in the garden and I could smell the herbs I was going to plant and see the cat and everything, but that wasn't what I was talking to $\mathrm{H}$ about and she was somewhere else, not having that experience. ... The part of your brain that has the phone call is the bit that thinks about what you are going to buy at the supermarket when you are walking to the tube in the morning. Sometimes you've got no recollection of walking to the tube. And it's that, when you are having a phone call. You might blank your immediate surroundings or you might be stroking the cat and enjoying the sunshine. It's almost like a membrane between the two. (BJ, roaming landline)

BJ captures the difference between the total immersion of HG's account and awareness of more than one space. She goes on to equate the call with reading (an activity known for its enchantments):

The phone call is verbal in the way that reading a book is verbal. It's all in words. It's not really happening in any immediate physical way. (BJ, roaming landline)

This is the same image HG gives:

Because you would just have the conversation, so it would just be a verbal thing. But in addition to that, like when you read a book, you have all of the things that go on in your brain. (HG, landline)

To sum up, an intense experience is possible when phoning, even if you are the one being called. It may involve sufficient 'bringing close' that the focus of the call becomes the other person and/or their environment and the immediate environment disappears; or the 'bringing close' may be a thread running simultaneously with a sensual awareness of the immediate world. The degree of projection varies.

Enchantment and the phone

Some interviewees referred to the phone itself in discussing their reactions. If we take the phenomenological approach, it follows that it is in periods of reflection, or breakdown, that the phone can make its presence felt. However, some accounts reveal moments that seem to dispose the recipient towards receiving a call. CS describes getting the gadget out of her pocket and flipping it round to see who is calling. She models the action during the interview:

So you did this action..?

I did and I probably felt a kind of pleasure like when you drink a cup of tea or sit down and its 'yup, that's pleasurable', quite apart from who it is to talk to and whether you want to talk to them or not. (CS, mobile)

SZ enjoys the feeling of connection that carrying the mobile phone gives him, something he remembers when he switches on and the call-back function informs him a message is waiting. Here we see delights akin to those described by [8].

Other pleasures relate to what the kit allows during the call:

The advantage is that your hands are both free ... If I had to answer a phone without a headset, then I have to hold it to my ear constantly which means I'm tied up and I don't know if you've ever tried making coffee one-handed but 
it's not easy, so I wouldn't do it. (AB, hands-free Bluetooth mobile)

There are also examples of direct disenchantment through design, where breakdown is clearly evident. Some concern the awkwardness of the kit:

It's too bulky. What I find really irritating is the way of answering a call is by pressing a button on the back of the earpiece. It's ...irritating to find. (CG, using a Bluetooth earpiece)

Some are more about social acceptability. Looking 'Star Trek' (AB, handsfree) is not desirable, and:

I felt a bit ridiculous. I don't use the phone enough to justify having a piece of plastic stuck to my ear. (CG, using a Bluetooth earpiece)

HG describes her experience using a mobile phone integrated with an MP3 player (headphones and a microphone at the neck):

I want to pick up the mouthpiece and hold it like that (gestures holding up mouthpiece and speaking into it) so that I don't look like I'm talking to myself when I'm walking down the street. (laughs) ... Yes, yes, because I'm mad but I don't want everyone to know I am. (HG, mobile with headset)

Another person with an MP3 player discusses the transition from music to phonecall:

Suddenly there's this really loud noise coming through telling you there's a phonecall. And it's a really nice part of the canal walk, and I'm listening to music, walking along and suddenly this really loud ring. ...very loud, very obnoxious, jarring. (CG, mobile with headset)

In conclusion, we can see that the technology and the design of its relationship to the body have an impact on the experience of the recipient - mostly during the answering of the call. And it varies from delight to total disenchantment.

\section{Transitions}

In addition to the effect of the kit, interviewees' accounts were full of the effect of their actions and expectations.

Things going on at the same time

In only two calls (of 24) was a participant's location the focus of the conversation. But for most interviewees, there were multiple and distinct spaces of concern involved, differentiated by the experiences that took place during the call and emerging from the activity of engaging with them. This proves particularly significant when the recipient is not fully in control of all the elements involved in the activities. Returning to CG's canal walk, we see that, at first, walking and talking is easily resolved:

How was it doing the walk and taking the call?

A lot quicker. Not really conscious of everything going on around me. ...conscious of it, but not taking it in. (CG, mobile with headset)

CG describes his walk, part of a daily routine. At a certain point he regularly considers the day to come. So not all his attention is in the immediate environment even before the call: he is already occupying multiple spaces. The phone call curtails some of this projection. While on the phone, he says, he cannot think ahead.

Then new divisions of attention emerge. As he walks, his concern starts to involve other people:

I prefer not to talk in close environments on my mobile phone: it seems a bit rude. ...[so] I pretty much timed the call to end at the train station. ... I need to be conscious of other things around me moving around and I wouldn't be able to focus on the call and people moving around me slowly while I am trying to walk very fast. (CG, mobile with 
headset)

Some part of his attention has remained ready to deal with the social dimensions of crossing the station, so that he can bring the call to a polite end before encountering this complexity. The spectre of this situation is something he premeditates even as he manages the call. Detailed questioning yields more about this balancing act:

I'd turn a particular corner and I'd know: nearing the station, call must end soon, wind up the call. (CG, mobile with headset)

At this point one can argue CG is partially immersed in several activities. His account reveals the juggling necessary as he moves into a new environment. He doesn't want to be so enthralled by the call that he cannot juggle.

Moving about is newly one of the many activities that can be interrupted by calls. Cooking, sleeping or stationary working have been interrupted by landlines for generations. In this case, the interruption did not halt the activity of moving about, but the recipient's circumstances affected the degree of enchantment desirable or achievable.

It is his desired relationship to the activities in the environment that is determining where his attention goes, not the fact that he is moving, per se. But moving about brings in local activities that regularly involve elements outside the recipient's control. Other examples, such as CS's ride on the upper deck of a bus with lots of luggage, further illustrate how moving (or being moved) affect the degree of commitment to an incoming call.

Living up to expectations

Not everyone answers their inconvenient calls. Talking of an unexpected call that she leaves to ring because she is driving, SL reveals further concerns:

I don't want to answer it 'cos I'm not necessarily in the right space to deal with whatever the person wants to know from me. ... I kind of like things to be in compartments. So I like to be in a scriptwriting space when someone rings me up about that. (SL, mobile)

This is more than balancing the demands of a call and the activities of the immediate environment. SL acknowledges there are activities that emerge from the activity of talking to the caller which require their own attention (i.e. space). SL wishes to deal with shared concerns in a space that relates appropriately to them - for instance, she later refers to wanting her diary to hand as part of being ready. What we learn is that, by ringing SL's mobile, the caller is prioritising the activity of talking to SL, whereas SL sees engagement in terms of the resulting shared activities and refuses contact. SL considers whether her response related to her expectation that the caller would be a unfamiliar caller talking about work. However, she concludes that she feels similarly about everyone.

Other references to reluctance/disengagement show further possible sources of concern. Having been told who is on the phone, SZ answers a call with part of his attention flying to the unfinished work that he expects the caller to be following up. (Un)readiness here is also wholly related to a projection of what the call is about.

The most curious case of disengagement through projection comes from someone who was fully engaged and inadvertently imagining her caller in the wrong physical location, until she was made aware of her mistake:

I did have that image of J. in the edit suite and then as the conversation progressed I realised she isn't there, she's told me she's checking into the plane. ...Sometimes you are just talking to someone and you hear a splash and you think 'oh my god, they're in the bath. NO!...you've just invaded my image...' Or you hear a car and they're somewhere different and that can be a jolt. (JM, landline)

JM reveals the degree of projection she engages in by recognising its breakdown. Here it is the caller's mobility that disrupts the enchantment.

These examples give a sense of the work being done as projection - not just in 'bringing close' another person, but in projecting into activities deriving from shared concerns. In looking at received calls, it is the imposition of this suite of activities that differentiates the recipient from the caller. The caller can choose which local circumstances to 
operate within. The caller can also set the call's agenda and define some of the spaces that the call's recipient will visit; spaces of concern that the caller can create at leisure prior to the call and which the recipient may attempt to premeditate. The recipient is projecting without conflicting demands, but the nature of the projection involves its own disenchantment. For whatever reason, the recipient does not willingly follow the caller into the expected spaces.

Anticipating who is ringing

Premeditation, seen above to be a significant part of the phoning experience, is clearest in the discovery that nine of the 10 interviewees were able to anticipate the caller for at least one call they described. This figure (just below half of all calls discussed) seems high but there was no surprise on the part of the interviewees that they should know who was ringing them. In many cases, it was not so much a 'booked' call as a correct assumption as to who was going to be at the other end. And, even when they did not actually want to talk to the person ringing, expectation made it less unpleasant. Again, Heidegger's explanation that our concern precedes our whereabouts and allows us to travel there fits: expected calls involve more anticipatory engagement; unexpected calls are harder to commit to.

LB answers an unexpected work call on his landline on a Sunday night, never recovers from his initial irritation and remains involved in a local activity throughout. Such reticent language is not typical when a call is expected:

When he rang, I didn't really want to take the call because I was quite tired. I didn't really want to take a call from anyone. I didn't know who it was going to be, either, so ... [During the call] my thoughts were: I want to talk about this later, I don't want to talk about this now. Keep it short. But I felt that we were talking round and round in circles all the time. ... I was fiddling with my computer. ... I was trying to carry on doing what I had been doing. But just at half speed because I was speaking as well. (LB, landline)

In fact, two interviewees spoke of reasserting control over their phone by letting a majority, including all unexpected calls, go straight to message. (One interviewee stopped herself mid-way through a description of the perfect phone design - one that makes calls but doesn't receive them - as she recognised the inconsistency of her demands.) Unexpected calls were deemed more intrusive than expected ones. In discussing intrusiveness, other significant factors appeared to be who was likely to call on which phone and for how long - both factors to some extent in the hands of the called. The landline enters the 'sacred' (SL) home space, and (especially on Sunday evenings) intrudes upon interviewees' rare peace.

\section{Discussion}

We have seen that landlines and mobiles can both function as a medium for enchantment; they can both provide a vehicle for projecting into someone else's world and engaging with a remote person. And though interference with this projection comes in many forms, only some pertain to the difference between the two modes of phone. A discussion of factors follows.

\section{Mobility}

The mobility of the mobile phone introduces a range of activities that can potentially interfere with enchantment, such as crowds to navigate, cars to drive and buses to alight. Further, mobility brings with it the likelihood of being in the wrong place, or surrounded by the wrong things, to deal most effectively with the call in hand. And this is particularly true for recipients. Whereas callers can choose their time and place and so limit interfering activities including movement itself should this be desirable - the recipient of the call can only choose to reject the call or manage competing activities.

\section{Personal space}

Mobile phones differ from landlines by becoming associated with the person. This association was captured in how the interviewees related to the equipment. But even where disenchantment was triggered by difficult or funnylooking kit, it swiftly vanished with engagement in the call. The other potential effect of introducing a phone into one's personal space might be an increased feeling of intrusion from the arrival of calls. But this proximity seemed to have little bearing on how intrusive calls felt. The mobile's well-documented tendency to embarrass in public appeared in the accounts implicitly as something to manage along with other social activities, but not as actively disenchanting. 
Control

The role of recipient is not an empowered one: as noted, the caller determines many elements, such as, indeed, the fact of the call. The accounts revealed that, on the whole, the call's recipient was most likely to be enchanted, all other things being equal, if they had some anticipation of the call and who was ringing. This is unsurprising, as it equates to being reinstated with some control and a chance to relinquish it gracefully. Anticipation offers a chance to be ready for a conversation with someone, both emotionally and practically, and to be in a space where other activities are less likely to compete. While this is true for all phones, mobiles are more challenging to manage than landlines. They are also more likely to have caller ID, a scant but nonetheless useful opportunity to prepare ahead of answering. It is worth noting that a side effect of using both the Bluetooth earpiece and the MP3 player headset is that it is no longer easily possible to see who is calling.

Other factors

A range of other contextual factors affected enchantment, regardless of the phone used. Someone unknown cannot captivate as easily as a familiar and welcome caller. And we have seen how a preference for compartmentalisation; the effect of an unfinished task; or a misreading of the mobility of the caller can have an effect. Each represents a different dimension of the experience of being called: the personal disposition of the recipient; the shared history of recipient and caller; the amount of information that the speakers make available to each other. None of this is ever the same twice.

\section{Design issues}

It is not the purpose of the paper to propose new designs for phones, but to raise interaction design issues in such a way that designers can better contemplate people's experience of phoning. It is possible to be totally enchanted by conversations using a mobile phone and engage in colourful and sometimes inaccurate projections that 'fill in the gaps' left by using a mono-dimensional medium. However, this level of engagement is not always appropriate and, even when it is, it can be hindered by poor understanding of what is involved.

Let us first acknowledge - and then move beyond - the level of usability. Comments on the fiddly Bluetooth earpiece show how the design of the equipment matters. And caller ID, a function beginning to be lost as the phone becomes more fractured and integrated with the body, is a small concession to people's comfort. It would seem retrogressive to overlook the matter of how information about the caller is offered across different orientations of device, given the value of anticipation.

From these insights it is a short step to more profound design challenges.

\section{Managing transitions}

Phone calls open up new activities for people being called. These activities involve a set of transitions, including paying attention to the ringing phone, anticipating who the caller is, reapportioning attention from the local context and any other projections taking place at that time (such as considering the day to come) to new spaces of activity, and only then answering the call.

Another set of transitions occurs because phones, in joining the paraphernalia of daily life, have started to integrate with other technologies. This introduces transitions such as that from music - providing a soundtrack to what is happening in the environment - to phone as, first, intrusion into that environment (ringing) and then a pull out of it (conversation). Television, the Web and other forms of information and entertainment are being incorporated into phones and all these offer different starting states for transition into what becomes the phoning experience.

At the moment, many transitions for calls' recipients might more aptly be called breakdowns in the phenomenological sense: producing a sudden loss of immersion in what was previously engaging. But this is not good design: the abruptness of breakdown is only welcomed as an alternative to being in danger. It is total disenchantment: the equivalent of lights up in the middle of a movie.

Most people in their accounts could be seen attempting to manage their transitions on and off the phone gracefully and adjusting their attention in subtle ways to accommodate the other demands on their notice. It is this gracefulness 
that good design should support. Not by taking the control out of people's hands, but by offering tools to manage phoning smoothly so that attention can flow from one concern to another. This would be to tune more finely the engaging experience that being on the phone has the potential to be, a potential illustrated above.

\section{Managing engagement}

But calls, especially those on the move, are likely to involve additional transitions, as the local environment changes around the recipient and invites the person to cope with complex physical and social negotiations. These changes increase the overhead of responding appropriately, in terms of role and equipment, but, more intrinsically, in terms of projection.

As noted, a rich experience of being on the phone is only sometimes appropriate, depending on activity, relationship and function of call. A caller's 'extended body', as portrayed by Feenberg and revealed - in phoning - through voice, is only of interest when the person is of interest and there is an absence of other distractions for the person receiving the call. If the local environment is demanding, there is less (satisfiable) desire to consider the other person in a rounded way; their words are enough. If there are few competitive interests, then the person at the other end may be filled out and sketched in. This flexibility to be engaged more or less, to use more or less attention, is a potential virtue of phoning; a virtue all the more important when considered beside the range of other activities, described above, that absorb the recipients of calls. But it is a flexibility that needs careful handling, as the failure of even hands-free phoning to provide a safe means of engagement during driving would seem to indicate.

Clearly as well as ensuring that transitions should be smooth where they occur between technologies, and between being off-the-phone and being on it, it is also a design challenge to support the managing of engagement and the transitions that occur as people's interests (and what they are coping with) shifts during calls. This is the biggest challenge of all because it is not related to any predictable external function. The design challenge is to enhance flexibility and to offer a simple means to the user to control it. And this flexibility needs to follow the phone as the phone follows the contours of the body, developing even closer links to ears, eyes (for texting, viewing data) and mouth, and ceasing to be a single gadget.

\section{Conclusion}

This paper has sought to contextualise phoning experiences as mobiles bring with them new practices. It has taken a phenomenological approach to accounts of 'being phoned' and used the concept of 'enchantment' as the undisturbed condition of phoning. The rest of the paper has thus framed discoveries in terms of what disenchants phone users.

The accounts collected and analysed as part of this study suggest that person-centred phoning has its own features and is qualitatively different in certain ways from location-centred phoning. However, they also suggest that the capacity of mobile phones to enchant does not differ intrinsically from that of the phones our parents used. And ringing phones are still annoying - not just because they go off in more embarrassing places than before, but because they are disruptive by nature.

By taking a phenomenological approach, it has been possible to consider movements in attention and projection into spaces ahead of actual activity and show that this can be more fruitful than considering movement as only a physical phenomenon. By framing the discussion with the concept of enchantment, we have gained access to its opposite: disenchantment, and the conditions that create it.

In the same way, it has been possible to look at the relationship between the phone and the person as both a physical association with particular design needs, and also as a flux of experiences: the phone coming in and out of view but, by and large, remaining inconspicuously absorbed in the activity of phoning. Viewing the integration of the phone experientially encourages design insights based on transparency and flow.

What distinguishes this study from many others is the emphasis placed on the phone as a two-way communication mechanism, triggered at any one time by one party and therefore giving rise to a highly asymmetric experience of engagement, projection and concern, for participants in a call. While phones are likely to remain an instrument controlled at outset by only one end; this consideration of what it is like to receive calls is intended to inspire design that lessens the disparity. 
The study reported here concerns itself with a group of people who grew up with landlines and only started to use mobiles in the last decade or so. It would be interesting to compare the responses of younger people for whom both types of phone were part of growing up. It might reveal a change in either the quantity or quality of engagement possible. Certainly the changing communication ecology, affected by the arrival of email and texting, needs to be considered if we are to learn more.

This study has been far from extensive and, while offering a new set of questions for designers, only touches upon the many subtleties that phoning involves. It is hoped that the analysis of people's accounts presented here is indicative of the many further studies that might profitably be carried out in extending research on mobile phone use.

[The landline] is a bit more like bread and butter and mobile phone is like pudding. ... I suppose our grandparents would have felt like that about the landline. (CS, on the mobile)

\section{Reference}

[1] Laurier E (2001) Why people say where they are during mobile phone calls. Environment and Planning D 19: pp 485- 504

[2] Weilenmann A (2003) "I can't talk now, I'm in a fitting room": Availability and Location in Mobile Phone Conversations. Environment and Planning A, 35 (9): pp 1589-1605

[3] Vincent J (2004) Are People affected by their Attachment to their Mobile Phone?. In Nyiri, K (ed) A sense of Place: the Global and the Local in Mobile Communication, Passagen Verlag, Vienna, pp 221-230

[4] Norman DA (1998) The Invisible Computer. MIT Press, Cambridge MA

[5] Thurlow C (2003) Generation Txt? The sociolinguistics of young people's text-messaging. Discourse Analysis Online: http://www.shu.ac.uk/daol/articles/v1/n1/a3/thurlow2002003-t.html

[6] Dant T (1999) Material Culture in the Social World; Values, Activities, Lifestyles. Open University Press, Buckingham, UK

[7] Berg S, Taylor AS, Harper R (2003) Mobile Phones for the Next Generation: Device Designs for Teenagers. In Proceedings of CHI 2003, pp 433-440

[8] McCarthy, J., Wright, P., Wallace, J.,

Dearden, A. (In Press). The experience of enchantment in human-computer interaction. Personal and Ubiquitous

Computing. Available at Online First:

http://www.springerlink.com/(2eed2yilfjxksvyf3v2wjv55)/app/home/issue.asp?referrer=parent\&backto=journal,1,31;b rowsepublicationsresults, 1224,1581

[9] Gant D, Kiesler S (2001) Blurring the Boundaries: Cell Phones, Mobility, and the Line between Work and Personal Life. In Brown, B et al (eds) Wireless World: social and interactional aspects of the mobile age, SpringerVerlag, New York, pp 121-131

[10] Weilenmann AH, Leuchovius P (2004) "I'm waiting where we met last time": exploring everyday positioning practices to inform design. In Proceedings of NordiCHI 2004, ACM, New York, pp 33-42

[11] Truch A, Hulme, M (2004) Exploring the Implications for Social Identity of the New Sociology of the Mobile Phone. Paper presented at The Global and the Local in Mobile Communications: Places, Images, People and Connections' Conference, Budapest, June 10-11, 2004

[12] Heidegger M (1927, 1962) Being and Time. Basil Blackwell, Oxford

[13] Dreyfus HL (1991) Being-in-the-World: A commentary on Heidegger's Being and Time Division 1. MIT Press, Cambridge MA

[14] Coyne R (2001) Technoromanticism: Digital narrative, holism and the romance of the real. MIT Press, Cambridge, MA

[15] Feenberg A (2003) Active and Passive Bodies: Comments on Don Ihde's Bodies in Technology. Techné ejournal, 7(2): http://scholar.lib.vt.edu/ejournals/SPT/v7n2/feenberg.html

[16] Bennett J (2001) The Enchantment of Modern Life: Attachments, Crossings, and Ethics. Princeton University Press, Princeton

[17] Schegloff EA (1972) Sequencing in conversational openings.In Gumperz JJ et al Directions in Sociolinguistics: The Ethnography of Communication. Holt, Rinehart and Winston, New York, pp 346-380

[18] Seamon D (2002) Phenomenology, Place, Environment, and Architecture: a review of the literature [HTML] http://www.phenomenologyonline.com/articles/seamon1.html

[19] Light A, Wakeman I (2001) Beyond the Interface: Users' Perceptions of Interaction and Audience on Websites. 
IwC 13: pp 325-351

[20] Light A (2006) Adding Method to Meaning: a technique for exploring peoples' experience with technology. BIT 25(2): pp 175-187 